23 Keywords:Cost-effective conservation;Replication; Conservation professionals; Conservation 24 planning; Optimization

\section{Abstract}

Despite extensive research demonstrating the benefits of applying cost-effective conservation techniques,such as optimization, a large gap remains between the evidence from research and the actions of professions as they design and implement conservation programs. This study examines this gap through an international survey of conservation professionals who are familiar with costeffective conservation techniques. The primary results of this study, replicate previous results from a smaller of agricultural preservation professionals, and show that the vast majority of survey respondents viewed cost-effectiveness as a virtue,but ultimately do not consider it as important as other program design criteria. These results reinforce the idea that advocates of cost-effective conservation need to address concerns about fairness and transparency and remedy gaps in the knowledge and expertise of professionals involved.Finally, thelack of incentive to conservation professionals to change their practices is a challenge that calls for public pressure and encouragement for experimentation and evidence-based policy to improve the cost effectiveness of conservation.

\title{
Understanding and Overcoming the Barriers for Cost-Effective Conservation
}




\section{Understanding and Overcoming the Barriers for Cost-Effective Conservation}

\section{Introduction}

Research has consistently shown that organizations with the most severely limited budgets have the most to gain from adopting cost-effective conservation (CEC). CEC is a project-selection process that incorporates both benefits and costs to maximize the conservation outcomes generated by available funds (see for instance, Underhill, 1994; Babcock et al., 1997; Balmford et al., 2000; Polasky et al., 2001; 2006; Sarkar et al., 2006).Over the past couple of decades, a substantial literature has developed that advocatesfor applying CEC techniques, such as optimization through mathematical programming, to enable conservation professionals to select a set of projects that maximizes the organizations objectivesfor a given budget (see for instance, Babcock et al., 1997;Polasky et al., 2001; Ferraro, 2003; Wu et al., 2001). Despite the many studies that have identified the benefits of CEC, conservation professionals remain wary (Arponen et al., 2010; Gowdy et al., 2010) and its application is limited. This lack of application is perplexing to economics, which has a core principal of studying the behavior given limited resources. Previous work by Messer et al. (2016a) suggests that part of the problem is that conservation professionals do not consider cost effectiveness a priority and lack incentives to adopt new practices that could improve the cost effectiveness of conservation efforts. This research seeks to replicate the approach used by Messer et al. (2016a) by expanding the sample to an international group of professionals engaged in a variety of conservation activities. This research thus addresses the question of why conservation practitioners, who have dedicated their professional lives to environmental conservation, have not adoptedcost effective selection techniques that would enable limited budgets to be further stretched to achieve greater environmental benefits. 
In general, CEC methods consider both the benefits and the costs associated with each potential project and identify a set of projects that provides the greatest aggregate benefit possible ("the most bang for the buck"). Optimization delivers CEC by using a set of mathematical programming algorithms adopted from operations research, including binary linear programming (BLP) and goal programming, to systematically address complexities (see for instance, Underhill, 1994; Babcock et al., 1997; Balmford et al., 2000; Polasky et al., 2001; 2006; Sarkar et al., 2006).Despite extensive research demonstrating the advantages of applying optimization techniques and efforts to acquaint conservation organizations with them, conservation professionals generally have not adopted cost-effective methods of project selection.

Currently, conservation programs throughout the world rely mostly on benefit-targeting (BT), also referred to as rank-based method(Babcock et al., 1997, Messer and Borchers, 2015). BT involve constructing an index of potential benefits and associated weights from offered projects. For example, US federal conservation efforts have typically used BT—such as the selections for acquisition to the national parks system and for forest preservation (Babcock et al., 1997, Wu et al.,forthcoming).BT ranks each project according to the environmental benefits provided and sequentially selects the highest-ranking projects until the budget is exhausted (Ferraro, 2003). BT performs best when the benefits of various projects vary more than the costs of those projects (Babcock et al., 1997). This benefit-only method is not cost-effective because it ignores cost as a selection criterion. BT can result in budgets quickly being exhausted by a few high-ranking but relatively expensive projects.

While optimization through mathematical programming will always achieve the highest aggregate benefits for a given budget (assuming that the benefits are measured accurately), 
72 another CEC technique is benefit-cost targeting (BCT) which selects projects with the largest

73 benefit-cost ratio until the budget is exhausted. BCT computes the greatest benefit per dollar and

74 achieves greater cost-effectiveness than BT (Babcock et al., 1997; Ferraro, 2003; Duke et al.

75 2015). In most cases, CEC and BCT will yield identical selection sets, except in cases involving

76 large budget remainders (Duke et al., 2013; Messer 2006). For instance in the context of

77 farmland conservation, Wang and Swallow 2016 found that BCT and optimization yielded very

78 similar outcomes when focusing on associated benefits and costs, parcel numbers, and number of

79 acres. These authors note that when a government or agency wants to achieve more specific

80 goals optimization is usually better than BCT. A handful of conservation programs at the state

81 level (Messer et al, 2016b) and the federal level (Wu et al., 2000; Wu et al., 2001) have used

82 variants of BCT to achieve CEC.

83 This research seeks to understand why CEC does not have widespread use by

84 conservation professionals. Researchers have pointed out several obstacles for CEC. For

85 instance, Sullivan et al. (2004) identified political process and perceptions of fairness by various

86 groups as major obstacles.Gardner (1977) argued for the importance of accurately measuring the

87 external benefitswhen designing conservation policies while other researchers have raised a

88 variety of concerns about the difficulty in accurately capturing and quantifying these

89 environmental amenities in the context of CEC (Arponen et al., 2010; Bryan 2010; Gowdy et al.,

90 2010; Bryan et al., 2011).Conservation professionals may resist adopting CEC methods because

91 they are not familiar with the mathematics used in optimizationor lack computer and software

92 tools needed to implement them (Ferraro and Pattanayak, 2006).Pullin et al. (2004) pointed out

93 that there exists a knowledge gap as conservation professionals do not have access to easily

94 understandable scientific information. Pull et al. (2004) also noted that conservation 
95 professionals often resist change and prefer to plan as they have in the past instead of

96 incorporating further information into their decision making process.Prendergast et al. (1999)

97 identified the lack of awareness of optimization methods and lack of understanding of how they

98 function as major obstacles to adoption.

Messer et al. (2016a) surveyed agricultural land professionals in Maryland and found that conservation professionals value transparency and fairness more than cost-effectiveness. This

101 study seeks to replicate this earlier research by expanding the sample bysurveying conservation 102 professionals from organizations that have a variety of conservation objectives, not just 103 agricultural preservation. Additionally, this study includes a broader sample of geographic 104 regions including conservational professionals who work in international contexts. This research 105 also helps address the so-called "replication crisis" in behavioral and social sciences. A growing 106 number of scholars have expressed concerns that published results in the behavioral sciences, 107 including economics, are frequently false (Ioannidis and Doucouliagos, 2013). Replication is a 108 cornerstone of science (Moonesinghe et al., 2007) and is something that needs to occur more 109 often in peer-reviewed articles (Hamermesh,2007). Replication is particularly important in the 110 context of research that has policy implications.

111 This study also contributes to the literature about the gap between the practices of 112 conservation professionals and the recommendations of researchers interested in CEC. 113 Importantly, this research studies the attitudes of conservation professionals who have been 114 educated about CEC techniques, yet still generally do not use them in their work. Thus, this 115 research provides important insights beyond the basic 'knowledge gap' arguments and suggests 116 that other factors need to be overcome before CEC will occur on a widespread basis. We 117 designed this study to address three primary objectives: 
1. Evaluate attitudes of conservation professionals about CEC.

2. Evaluate whether these attitudes varied by the type of conservation activity.

3. Identify barriers that discourage conservation professionals from adopting CEC and determine what, if anything, can be done to overcome them.

The results of this study demonstrate that the vast majority of survey respondents viewed cost-effectiveness as a virtue in program design but did not consider it as important as other program design criteria. In particular, respondents emphasize the important of fairness and transparency of the selection process. A major obstacle for adoption CEC isthe lack of incentives to change existing programsas respondents seem to receive little public pressure to be costeffective nor receive additional recognition or financial award in their work for making their conservation programs more cost-effective.Finally, respondentsindicated that their likelihood of adoption of cost-effective conservation would increase if they can receive additional training and software to facilitate adoption ofCEC.

\section{Research Methods}

We developed the survey using the Qualtricssoftware. We identified valid email address for246conservation professionals from around the world whohad attended lectures on CEC techniquespresented by the study co-authors. This list of participants (see Appendix A for the organizations represented by the participants) was derived from attendance lists of 47 presentations thatwere madeat the National Conservation Training Center, the Land Trust 
137 Alliance Rally, the American Farmland Trust conference, and offices of nonprofit and 138 government agencies. ${ }^{1}$

Since the sample population came from people who had previously attended lectures on

140 CEC techniques, this sample is certainly not a representative sample of all conservation

141 professionals worldwide. Instead, we selected this sample because it helps address the question

142 of why, even once educated about the virtues and techniques of cost effective, conservation

143 professionals are not adopting these approaches. Consequently, this research can move beyond

144 the simple explanation that conservation professionals are not adopting these approaches because

145 they are do not know they exist, but can instead dig deeper about what organizational and

146 attitudinal barriers continue to exist to CEC.

The recruitment process consisted of emailing a surveythat consisted of 43 questions to246 individuals. To encourage people to respond to the survey, we incentivized participation

149 in the form of a raffle of one \$250 Amazon gift cards and four \$50 Amazon gift cards.

150 Recipients of the gift cards were to be chosen randomly after the survey had been completed.All 151 respondents were also offered the opportunity to donate the money to a nonprofit organization of 152 their choice, this option was made available as we anticipated that some government employees 153 would not be able to receive direct financial payment, but might still be motivated to participate 154 by donating the money.

156 on follow-up reminders.One week after the initial email, we sent a reminder email to anyone

157 who had not yet responded and included the 43-question survey (Appendix B). The following

\footnotetext{
${ }^{1}$ Note that this study design differs from that of Messer et al. (2016a), which surveyed people shortly after seeing a presentation about cost effective conservation.
} 
158 week, we sent a second reminder email to all non-responders again asking them to participate in

159 the full-length survey. The versions of the survey were attached to that reminder. One week after

160 that, we sent a final reminder email to all non-responders.For people who did not respond to the

161 longer survey after several attempts, we sent a shorter version of the survey (Appendix C). This

162 version covered the main questions of our research and focused on how willing conservation

163 professionals were to adopting optimization and what obstacles inhibit them from adopting this

164 technique.

Twenty-four of the original email addresses proved to be nonfunctional, reducing the

166 number of professionals contacted to 246. The rate of response to the initial survey request was

$16726.4 \%$. After completion of all of the follow-up emails, we had obtained responses from 85

168 individuals, representing a final response rate of 34.6\%. The 85 responses consist of 65 from the

169 long surveyand 20 from the short survey.

\section{$170 \quad$ 3. Results}

171 At the beginning of the survey, respondents were asked to rate their knowledge of their own 172 conservation programs on a scale of 1 (not knowledgeable) to 5 (expert). All of the respondents

173 reported having expert or near expert knowledge with an average rating of 4.52. In terms of 174 familiarity with optimization generally, which was rated on a scale of 1(not at all) to 5 (very 175 well), the average response was 3.14.Respondents who had heard a presentation on optimization 176 rated their retention of the material presented fairly high—an average of 3.58 on a scale of 1

177 (remember nothing) to 5 (remember most of the information). Similarly, respondents who had 178 read information on optimization techniques reported an average retention rating of 3.32. 
Avery high percentage of respondents viewedoptimization as a good idea(91\%).

180 However, only 55.4\% thought it was applicable to their organizations, while 39\% said that they 181 did not know whether optimization would be applicable to their organization. Respondents were 182 asked to ratethe importance of five criteriaon a scale of 1 (not important) to 5 (very important) in 183 theirproject selection processes:

(1) Knowledge (knowledge of the staff in how to use the selection process to identify good projects);

(2) Fairness (fairness to applicants);

(3) Transparency (ease of explanation to public, advisory board, potential applicants, etc.);

(4) Cost-effectiveness (achieve the largest possible social benefit for a relatively low price), and

(5) Ease (ease of administration).

As shown in Figure 1, fairness to applicants was the most important criterion(average score of 4.23). The second most important criterion (average score of 4.14) was transparency, which was described in the survey as theease of explaining the process to various interest groups.Knowledge of staff ranked third (average score of 4.07). Interestingly,the costeffectiveness of the process (described as achieving the largest possible total benefit for a relatively low price), while considered an important criterion, was ranked lowest (average score of 3.92) despite most conservation programs’ limited budgets. We performeda two-tailedpaired t-testfordifferences in the means between the criteria. The results showed statistically significant 
200 differences between fairness and cost-effectiveness $(\mathrm{p}=0.021)$. In addition, there are statistical

201 significant differences between transparency and cost-effectiveness $(p=0.014)$. Other differences

202 in means between the criteria were found to not be statistical significant.

203 
204 Figure 1: Importance of Criteria in the Project Selection Process

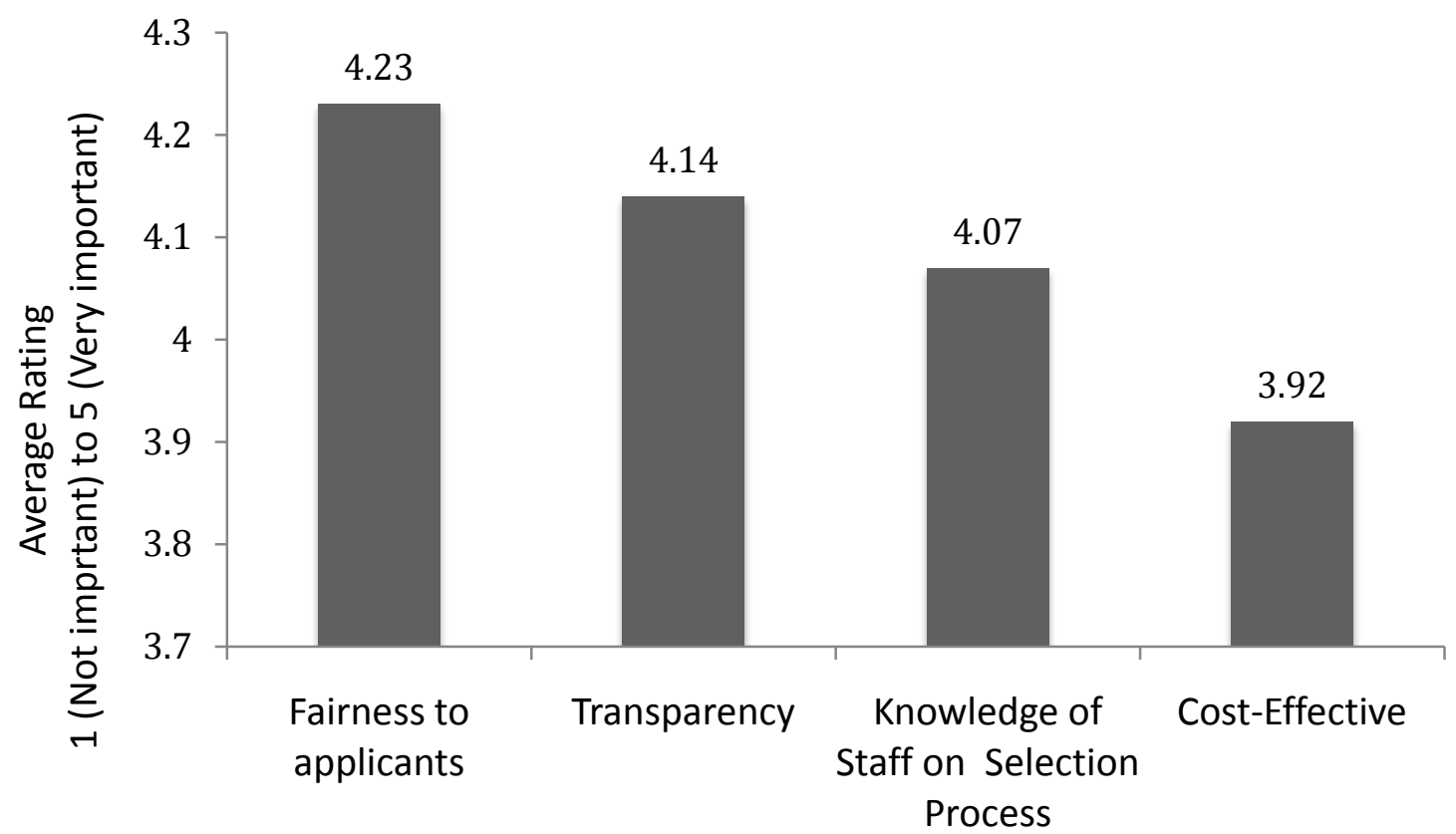

Several survey questions sought to evaluate the degree of difficulty of the challenges that

207 have been associated with adopting optimization: Respondents rated the difficulty of each on a

208 scale from 1 (not difficult) to 5 (very difficult) and the results are shown in Table1. The lack of

209 an incentive to justify a change in the method used was seen as the biggest obstacle to adopting

210 optimization (average rating of 3.55), followed by the initial cost of technical resources (3.46).

211 Lack of previous experience with optimization was rated as least challenging(2.72). A two-tailed

212 paired t-test was used to evaluatethe difference in the meansof lack of incentive and lack of

213 previous experience. This difference was statistically significant at the 0.01 level. 
215 Table 1. Difficulty of the Potential Obstacles to Adopting Cost Effective Conservation, 216 Descriptive Statistics.

Question 18: "Assess the difficulty of the following potential obstacles for adoption optimization as the selection process in your organization's

Standard conservation program:

Lack of incentives to justify a change in process (Lack Incentives)

Initial cost of technical resources costs (software and staff training) (Initial Cost)

Difficulty in measuring benefits (Measure Benefits)

Possibly forgoing the ‘best’ project regardless of cost(Forgo Best Project)

Need for accurate cost information at the time of selection(Need Cost Information)

Administration of the process(Administration Process)

Lack of availability of technical resources(Lack Technology)

Time to implement the process(Time to Implement)

Due to Federal guidelines/ restrictions(Process Not Staff Determined)

Lack of previous experience(Lack of Experience) optimization would be influenced by the availability of additional resources, such as userfriendly software and training. From an initial willingness of 2.95 (on a scale of 1 to 5), access to

221 software raised average willingness to adopt to 3.34, a 13\% increase, and access to both software

222 and training raised willingness to adopt an additional 9\% to 3.63 (Table 2). This result

223 demonstrates an important avenue by which adoption of optimization techniques could be

224 increased, allowing conservation organizations to be more cost-effective. ${ }^{2}$ Results of two tailed

225 paired t-tests, showed statistically significant increases in willingness to adopt in response to

\footnotetext{
${ }^{2}$ To our knowledge, no environmental or conservation foundation or funder is currently providing this type of training.
} 
226 access to such resources. There was no statistical significance between an Excel-based platform

227 or an internet- based optimization platform $(p=1.0)$. We found that all types of resources were

228 significantly different from willingness to adopt with no resources.Furthermore, we find there are

229 statistically significant differences between access to training and software (Training Access)

230 and only given access to an Excel based platform (Excel Access) $(\mathrm{p}=0.003)$. In addition, we

231 found that there is a statistical significant difference betweenTraining Access and access to an

232 web based platform (Web Access) $(\mathrm{p}<0.001)$. Lastly, we also find there are statistical significant

233 differences between given only access to software (Software Access) and being given access to

234 software and training (Training Access) $(\mathrm{p}<0.001)$.

235 
Table 2. Willingness to Adopt Optimization

\begin{tabular}{llcc} 
Variable & Survey Question & $\begin{array}{l}\text { Standard } \\
\text { Deviation }\end{array}$ \\
\hline$\underline{\text { Willingness to Adopt }}$ & $\begin{array}{l}\text { How willing do you think your organization } \\
\text { Optimization }\end{array}$ & 2.93 & 1.011 \\
& $\begin{array}{l}\text { would be to adopt optimization as the selection } \\
\text { process for your conservation program in the } \\
\text { future? }\end{array}$ & &
\end{tabular}

$\underline{\text { Excel Access }}$

If your organization was given access to user-

friendly Excel-based software to help

implement optimization, how willing do you

think your organization would be to adopt

optimizationin the future?

$\underline{\text { Web Access }}$

If your organization was given access to user-

3.38

0.871 friendly web-based software to help implement optimization, how willing do you think your organization would be to adopt optimizationin the future?

$\underline{\text { Software Access }}$

If your organization was given access to user-

friendly software to help implement optimization, how willing do you think your organization would be to adopt optimizationin the future?

$\underline{\text { Training Access }}$

If your organization was given access to $A N D$ trainingfor user-friendly software to help implement optimization, how willing do you think your organization would be to adopt optimizationin the future? 
We also conducted an analysis of factors that influence conservation professionals'

239 willingness to adopt optimization as theirprimary selection process. Ordered probit

240 modelswereused to analyze the relationships between willingness to adopt optimization and

241 independent variables. As shown in Table 3, we conducted two models, Model 1 looks at the

242 willingness to adopt optimization and eight independent variables. Model 2 includes variables

243 related to the difficulty in measuring benefits, organizational variables, and the likelihood of

244 adoption the Logic Scoring of Preferences (LSP) to help quantify benefits.

245 LSP is a technique originally developed in computer science to help develop project

246 selection criteria and corresponding weightings. LSP incorporates fundamental properties of

247 human reasoning and seeks to develop a means for measuring project benefits in a way that

248 corresponds to the intent of decision makers (Dujmović, 2007, Allen et al., 2011).Since questions

249 about organization type, LSP and benefit measures were not included in the short survey, Model

2502 has a smaller sample size. The data set for the analysis consisted of observations, from

251 respondents who had some previous knowledge of optimization.

252 In Model 1, we estimate the impact of eight independent variables on conservation 253 professionals' willingness to adopt optimization. The independent variables in Model 1 are

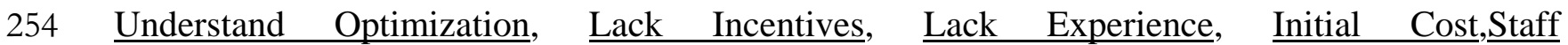

255 knowledge, Fairness Importance, Transparency Importance, and Forgo Best Project. The

256 Understand Optimizationvariable is the response to the question that asked respondents to rate

257 their understanding of optimization from 1 (not at all) to 5 (very well). We included these

258 independent variables in the model, because we expected them to have an impact on

259 conservation professionals’ willingness to adopt optimization. For instance, as the understanding 
260 of optimization increases (Understand Optimization), we would expect to observe a greater 261 willingness to adopt optimization.

All seven other independent variables included in the model came from a survey question

263 asking respondents to rate each item on a scale of 1 (not difficult / not very important) to 5 (very 264 difficult / very important).The Lack Incentivesvariable addresses the perceived difficulty of 265 changing the project selection process to optimization due to a lack of incentive to justify this 266 switch. We expect that having a lack of incentive to change will be common in government 267 organizations and will decrease the likelihood of adopting optimization. The Lack 268 Experiencevariable addresses the perceived difficulty of adopting optimization due to lack of 269 previous experience using this method. Similarly, we expect if lack of experience is a large 270 obstacle, than there will be less willingness to adopt optimization. The Initial Costvariable 271 addresses the potential that participants perceive CEC optimization as being more expensive for 272 the organization due to the costs of staff training and related software.We expect to see initial 273 cost of technical resources to be a significant reason why conservation professionals are not 274 adopting optimization. The Staff Knowledge Importancevariable addresses how important it is 275 that the staff understand how to use the selection process. The Fairness Importancevariable 276 addresses how important fairnessto applicants is for selection process. We expect willingness of 277 adoption to increase if fairness is an important criterion to many conservation professionals. 278 TheTransparencyImportancevariable addresses how important transparency is for selection 279 process. The concept of transparency was explained to the survey respondents as the ease of 280 explanation to the public, advisory board, and potential applicants. Since optimization generally 281 does not take into count transparency, we expect willingness of adoption to decrease if 282 transparency is an important criterion.The Forgo Best Projectvariable addresses the perceived 
283 difficulty of adopting optimization since, unlike Benefit Targeting, optimization can frequently 284 forgo the highest scoring conservation project, especially when those projects have relatively 285 high costs. We expect that conservation professionals will be reluctant to forgo high costs, 286 especially those facing imminent development (Messer and Borchers, 2015), therefore this 287 would be an obstacle for adopting CEC.

As shown in Model 1 in Table3, six of the independent variables were significant at the $2895 \%$ level.Four independent variables positively affect willingness to adopt optimization, while 290 two have a negative impact. We will begin discussing the variables with positive coefficients. 
292 Table 3. Ordered Probit Regressions on Willingness to Adopt Optimization.

\begin{tabular}{|c|c|c|}
\hline & Model 1 & Model 2 \\
\hline UnderstandOptimization & $\begin{array}{c}0.591 * * * \\
(0.126)\end{array}$ & $\begin{array}{c}0.592 * * * \\
(0.163)\end{array}$ \\
\hline$\underline{\text { LackIncentives }}$ & $\begin{array}{c}-0.533^{* * * *} \\
(0.128)\end{array}$ & $\begin{array}{c}-0.504^{* * * *} \\
(0.200)\end{array}$ \\
\hline LackExperience & $\begin{array}{l}-0.018 \\
(0.148)\end{array}$ & $\begin{array}{r}0.095 \\
(0.184)\end{array}$ \\
\hline InitialCost & $\begin{array}{r}0.0895 \\
(0.097)\end{array}$ & $\begin{array}{r}0.130 \\
(0.154)\end{array}$ \\
\hline$\underline{\text { StaffKnowledgeImportance }}$ & $\begin{array}{l}0.364^{* *} \\
(0.171)\end{array}$ & $\begin{array}{r}0.309 \\
(0.190)\end{array}$ \\
\hline FairnessImportance & $\begin{array}{r}0.285^{*} \\
(0.119)\end{array}$ & $\begin{array}{r}0.285 \\
(0.154)\end{array}$ \\
\hline TransparencyImportance & $\begin{array}{c}-0.541^{* * * *} \\
(0.225)\end{array}$ & $\begin{array}{c}-0.635^{* *} \\
(0.262)\end{array}$ \\
\hline Forgo Best Project & $\begin{array}{l}0.293^{* *} \\
(0.139)\end{array}$ & $\begin{array}{r}0.322 \\
(0.227)\end{array}$ \\
\hline Measure Benefits & & $\begin{array}{c}-0.374^{* *} \\
(0.159)\end{array}$ \\
\hline Willingness to Adopt LSP & & $\begin{array}{l}0.486^{* *} \\
(0.235)\end{array}$ \\
\hline Local Government & & $\begin{array}{l}-.865 \\
(.454)\end{array}$ \\
\hline Federal Government & & $\begin{array}{c}-.548 \\
(.578)\end{array}$ \\
\hline$\underline{\text { State Government }}$ & & $\begin{array}{l}-.121 \\
(.719)\end{array}$ \\
\hline Non-Profit & & $\begin{array}{l}-.985^{*} \\
(.484)\end{array}$ \\
\hline Observations & 73 & 51 \\
\hline $\begin{array}{l}\text { Pseudo R2 } \\
\text { Wald chi-square (10) }\end{array}$ & $\begin{array}{r}.212 \\
54.01\end{array}$ & .352 \\
\hline Wald chi-square (14) & & 63.82 \\
\hline Prob $>$ chi-square $=$ & 0.0000 & 0.0000 \\
\hline
\end{tabular}

Notes: *signifies significant at $10 \%$ level. ${ }^{* *}$ signifies significant at $5 \%$

level. ${ }^{* * *}$ signifies significant at $1 \%$ level. 
First, willingness to adopt optimization (Understand Optimization) increases with 296 respondents understanding of optimization. Recall that the respondents had a generally good 297 understanding of optimization (the average rating of understanding was 3.14), which is not 298 surprising considering our international sample of professionals had all been exposed to 299 information about the value of CEC techniques relative to BT.

300 Second, respondents who emphasized staff knowledge of the selection 301 process(StaffKnowledgeImportance)aremore willing to adopt optimization. In the survey, the 302 average rating of staff knowledge importance was 4.07. Thus, respondents seemed to be 303 relatively confident that their organizations could easily learn to incorporate optimization by 304 teaching their staff about the selection process.

Third, respondents who emphasized a fair process as important (ㅍairness Importance)

306 (average rating was 4.23) were more willing to adopt optimization. In this context, fairness to 307 applicants can be definedas the organization showing no bias and have the conservation project 308 given the same consideration to each project and applicant. It makes sense that individuals who 309 want to be fair are more likely to use optimization, which eliminates political considerations and 310 biases and analyzes each potential project using the same mathematical method.

311 Fourth, a surprising positive coefficient was the coefficient related to the relative 312 difficulty of foregoing the highest-ranking projects (ForgoBestProject). This suggests a rather 313 contradictory idea that the less willing they were to forego the best available projects, the more 314 likely respondents were to adopt optimization.The average rating of the difficulty of this obstacle 315 was 3.22 (representing "somewhat" difficult). A possible explanation for this result is that 316 respondents may have already been passing on the highest-ranking projects due to political 
317 pressures and thought that switching to CEC might make the process less political and thus better

318 outcomes would result. As noted in Duke et al. (2013, p. 128), “nongovernmental organizations

319 may win political favors or improve fundraising by, at times, focusing on high-profile projects,

320 even if they come at a relatively high cost.” to switchandtransparency of the process (TransparencyImportance) are significant and negative. Lack of incentives was rated as most challenging of the obstacles listed (average rating of 3.55). This could be because theorganizations, the public, and/or their donors arenot demanding that 325 these programs be more cost-effective. Alternatively, the program administrators may be

326 reflecting the incentive structures common to most government agencies and non-governmental 327 organizations that do not reward staff for being more cost-effective. When asked to evaluate 328 how cost-effective their organization's current selection processes, the average rating was 329 3.76out of 5 (somewhat cost-effective); therefore, many of the respondents viewed their current 330 processes as less cost-effective than they could be. Change tends to bedifficult and thus is 331 unlikely to occur without some kind of incentive provided to the staff involved with 332 implementing CEC.

The coefficient fortransparency in the selection process was negative sowillingness to 334 adopt optimization declined with the importanceof having a transparent process. Recall that this 335 criterion had a relatively high average rating of 4.14 . This result may be related to the perceived 336 complexityof optimization methods, which could be viewed as confusing by the organization’s 337 staff and thus difficult to explain to stakeholders. These concerns might be alleviated by using 338 BCT, since it only uses simple ratios of benefits and costs, instead of mathematical programming 339 as a means of achieving CEC. 
The results of Model 1 show that thelack of experience and the initial cost of implementing optimization were not significant. These results are particularly interesting since conservation programs often have limited budgets. Since all of the respondents in this data set

343 had been exposed to at least one presentation on optimization, their awareness of the method and 344 availability of free or inexpensive software packages may have reduced their concerns about 345 cost.

Table 3 also reports on a second model that includes variables related to the difficulty in 347 measuring benefits, organizational type, and the likelihood of adoption LSP to help quantify 348 benefits.Several of the results of Model 2 are similar to those shown in Model 1; and the overall 349 explanatory power of Model 2 rose by $14 \%$ compared to Model 1 . In Model 2, the coefficient 350 forthe variable related to the difficulty of measuring benefits was statistical significant and 351 negative at the $5 \%$ level. This indicates that respondents who view benefit measurement as 352 challenging are less likely to adopt optimization. This result makes sense because optimization 353 requires that numeric valuesbe assigned to all benefits. If conservation professionals already find 354 it difficult to capture measures of benefits, they are unlikely to use a method that makes this a 355 requirement. The coefficient for willingness to adopt LSP was positive and statistically 356 significant at the 5\% level.This suggests that the more willing respondents are to adopt LSP, the 357 more willing they are to adopt optimization which makes sense as LSP is designed to help make 358 various benefit measures more quantifiable (Dujmović and Allen, 2011; Allen et al., 2011). In 359 Model 2, the variables related to staff knowledge and the importance of fairness are no longer 360 statistically significant. Finally, the coefficient for Non-Profit was negative and significant at the 3610.01 level. This suggests professionals who work for non-profit organizations are less likely to 362 adopt optimization, likely due to the fact that non-profit organizations tend to be donation driven 
363 and do not have the pools of yearly funds available to select amongst a variety of available 364 projects.

\section{Conclusion}

366 Despite extensive research demonstrating the advantages of applying cost-effective conservation

367 (CEC) techniques, such as optimization, conservation organizations generally have not adopted 368 such methods and continue to use less cost-effective techniques such as benefit targeting (BT). 369 This lack of application is perplexing to economics, which has a core principal of studying the 370 behavior given limited resources. In response to this situation, researchers have identified a 371 number of potential obstacles to adoption including concerns about the fairness and transparency 372 of such methods, political considerations, challenges of measuring environmental benefits, 373 adverse incentives within public bureaucracies, and lack of awareness and understanding of 374 optimization.

This research surveyed conservation professionals who had been educated about CEC.

376 The advantage of this sample is that it enabled the research to focus on a group of education 377 conservation professionals that has otherwise not been studied; however, this sample does limit 378 the generalizability of the results to the broader conservation professionals who have not 379 attended trainings. Future research on this broader population and what is inhibiting these 380 professionals from adopting cost effective conservation is warranted.

Similar to the results found in Messer et al. (2016a), in this study while the vast majority

382 of thesurvey respondents indicate that cost-effectiveness is a virtue in conservation programs, 383 they do not consider it as important as other program design criteria. The results point not to one 384 particular barrier that predominantly impedes adoption, but to a handful of significant issues that 
385 need to be addressed. We find that concerns about fairness and transparency of the process, a

386 lack of confidence in the organization's ability to understand and use optimization, and a lack of

387 incentives to change the method currently used to a more cost-effective approach all have an

388 impact on willingness to adopt optimization.These results also replicate the findings of Messer et

389 al. (2016a) that suggest that expanding training efforts to introduce optimization to conservation

390 professionals and providing user-friendly software are likely to be crucial in promoting CEC

391 methods.The replication of the results of the earlier study, suggests that these findings are robust

392 and that philanthropic foundations and government agencies should consider investing in

393 trainings and software development.

394 These results also suggest that public pressure may need to be applied to conservation

395 professionals to make them more responsive to concerns about cost effectiveness. Interestingly,

396 this pressure could come from either side of the political spectrum as environmental advocates

397 want to see more on-the-ground conservation given the limited funds available and good

398 governance advocates want to see taxpayer moneyused as effectively as possible. Since some of

399 the statutes that created government conservation programs call for the efforts to be conducted in

400 a way that maximizes conservation benefits, the continued failure of some of these groups to use

401 CEC methods may make them vulnerable to legal challenges. Finally, given recent federal

402 efforts to encourage federal agencies to develop evidence-based policy and programs, efforts

403 should be undertaken to use randomized controlled trials to test various selection methods and

404 see how best to overcome the identified obstacles currently inhibiting the adoption of cost 405 effective conservation. 
407 Acknowledgements

408 This research was supported by the National Science Foundation EPSCoR Grant No. IIA-

4091301765 and the USDA ERS funded Center for Behavioral and Experimental Agri-

410 Environmental Research (CBEAR). We would like to thank Maik Kecinski for his insights when

411 developing this manuscript.

412 


\section{References}

414 Allen, W.L., Amundsen, O.M., Dujmović, J.J., Messer, K.D., 2011. Identifying and selecting

415 strategicmitigation opportunities: Criteria design and project evaluation using logic scoring

416 ofpreference and optimization. Journal of Conservation Planning 7: 61-68.

417 Arponen, A., Cabeza, M., Eklund, J., Kujala, H., Lehtomaki, J., 2010. Costs of integrating

418 economics and conservation planning. Conservation Biology 24: 1198-1204.

419 Babcock, B.A., Lakshminarayan, P.G., Wu, J.,Zilberman, D., 1997. Targeting tools for the 420 purchase of environmental amenities. Land Economics 73: 325-339.

421 Balmford, A., Gaston, K.J., Rodrigues, A.S.L, James, A., 2000. Integration of costs of 422 conservation intointernational priority setting. Conservation Biology 14: 567-605.

423 Bryan, B. A., Raymond, C., Crossman, N. D., \& King, D. 2011."Comparing spatially explicit 424 ecological and social values for natural areas to identify effective conservation 425 strategies."Conservation Biology 25.1: 172-181.

426 Bryan, B. A. 2010. "Development and application of a model for robust, cost-effective 427 investment in natural capital and ecosystem services." Biological Conservation 143.7: 1737$428 \quad 1750$.

429 Dillman, D.A., 1978. Mail and telephone surveys: The total design method. New York: John $430 \quad$ Wiley \& Sons.

431 Dujmović, J.J., Continuous Preference Logic for System Evaluation. 2007. IEEE Transactions on $432 \quad$ Fuzzy Systems, 15(6): 1082-1099, December. 
433 Dujmović, J.J., Allen, W.L., 2011. “A family of soft computing decision models for selecting

434 multi-species habitat mitigation projects.” World Conference on Soft Computing, San

$435 \quad$ Francisco, May 2011.

436 Duke, J.M., Dundas, S.J., Messer, K.D., 2013. “Cost-effective conservation planning: Lessons

437 from economics.” Journal of Environmental Management125: 126-133.

438 Duke, J.M., Dundas, S.J., Johnston, R., and Messer, K.D., 2015. “The effect of spatial

439 interdependencies on prioritization and payments for environmental services.” Land Use

$440 \quad$ Policy 48: 341-350.

441 Ferraro, P.J., Pattanayak, S.K., 2006. “Money for nothing? A call for empirical evaluation of 442 biodiversity conservation investments.” PLoSBiology4(4), e105.

443 Ferraro, P.J. 2003. “Assigning priority to environmental policy interventions in a

444 heterogeneousworld.” Journal of Policy Analysis and Management 22.1: 27-43.

445 Gardner, B.D., 1977. “The economics of agricultural land preservation.”American Journal of $446 \quad$ Agricultural Economics 59: 1027-1036.

447 Gowdy, J., Hall, C., Klitgaard, K., Krall, L., 2010."What every conservation biologist should 448 know about economic theory.”Conservation Biology 24: 1440-1447.

449 Hamermesh, D.S., 2007. Viewpoint: Replication in economics. Canadian Journal of $450 \quad$ Economics/Revue canadienned'économique 40: 715-733.

451 Ioannidis, J., Doucouliagos, C., 2013. What's To Know About The Credibility Of Empirical $452 \quad$ Economics? Journal of Economic Surveys 27: 997-1004. 
453 Messer, K.D. 2006. “The Conservation Benefits of Cost-Effective Land Acquisition: A Case

454 Study in Maryland.” Journal of Environmental Management 79:305-315.

455 Messer K.D., W. Allen, M. Kecinski, and C. Chen. 2016a. “Agricultural Preservation

456 Professionals' Perception and Attitudes about Cost-effective Land Selection

457 Methods.” Journal of Soil \& Water Conservation. 71(2):148-155.

458 Messer K.D and A. Borchers. 2015. “Choice for Goods under Threat of Destruction.”Economic 459 Letters. 135: 137-140. doi:10.1016/j.econlet.2015.07.026.

460 Messer, K.D., M. Kecinski, X. Tang, and R. Hirsch. 2016b. “Applying Multiple Knapsack 461 Optimization to Improve the Cost Effectiveness of Land Conservation.”Land Economics. 462 92(1):117-130.

463 Moonesinghe, R., Khoury, M.J., Janssens, A.C.J., 2007. Most published research findings are 464 false-but a little replication goes a long way. PLoS Medicine 4: e28.

465 Polasky, S., Camm, J.D., Garber-Yonts, B., 2001. "Selecting biological reserves cost-effectively: 466 An application to terrestrial vertebrate conservation in Oregon.”Land Economics77(1): 68$467 \quad 78$.

468 Prendergast, J.R., Quinn, R.M., Lawton, J.H., 1999. “The gaps between theory and practice in 469 selecting nature reserves.” Conservation Biology 13(3): 484-492.

470 Pullin, Andrew S., et al., 2004. “Do conservation managers use scientific evidence to support 471 their decision-making?’Biological conservation 119.2:245-252.

472 Sarkar, S., et al.,2006. “Biodiversity conservation planning tools: Present status andchallenges 473 forthe future.” Annual Review of Environmental Resources 31:123-159. 
474 Sullivan, P., et al., 2004.“The conservation reserve program: Economic implications for 475 ruralAmerica.” Agricultural Economic Report 834, U.S. Department of Agriculture $476 \quad$ Economic Research Service.

477 Underhill, L.G., 1994. “Optimal and suboptimal reserve selection algorithms.”Biological $478 \quad$ Conservation 70(1):85-87.

479 Wang, H.,Swallow, B.M., 2016. “Optimizing expenditures for agricultural land conservation: 480 Spatially-explicit estimation of benefits, budgets, costs, and targets.” Land Use Policy59: $481 \quad 272-283$.

482 Wu, J., Adams, R.M., Boggess, W.G., 2000. “Cumulative effects and optimal targetingof 483 conservation efforts: steelhead trout habitat enhancement in Oregon.”American Journal of $484 \quad$ Agricultural Economics 82: 400-413.

485 Wu, J., Zilberman, D., Babcock, B.A., 2001. “Environmental and distributional impactsof 486 conservation targeting strategies.”Journal of Environmental Economics and Management. 487 41(3), 333-350.

488 Wu, S., J. Toussaint, Messer, K.D., Forthcoming. "Maximizing Benefits in Project Selection: A 489 Hybrid Approach” Applied Economics. 


\section{Appendix A - Conservation Organizations Surveyed}

1. Alachua County

2. Baltimore County Department of Environmental Protection and Sustainability

3. Black Swamp Conservancy

4. Board of County Commissioners of Washington County, Maryland

5. Burlington County Resource Conservation

6. Cambria County Conservation District

7. Charles County

8. Chester County (PA) Department of Open Space Preservation

9. Chicago Wilderness

10. City of Des Moines, Iowa

11. City of Des Moines, Iowa (Forestry Division)

12. Colorado State University - Center for Environmental Management of Military Lands (CEMML) at Fort Campbell, KY

13. Colorado State University

14. Delaware Department of Agriculture

15. Delaware Division of Parks and Recreation

16. Duke Farms Foundation

17. Environmental Education, Conservation and Research (EECORE) Cameron

18. Estes Valley Land Trust

19. Federal Highway Administration

20. Florida Department of Environmental Protection

21. Frederick County Government, Maryland

22. Fund for Women

23. Garrett County Planning \& Land Development

24. Great Land Trust

25. Green Farm CO2FREE

26. Hill Country Conservancy

27. InstitutoAção VerdeInstitute Aí_í́̇o Verde

28. Inter-American Development Bank IDB

29. Jefferson County West Virginia Departments of Planning and Zoning

30. Kent County, Delaware Department of Planning and Zoning

31. Legacy Land Conservation Program, Dept. of Land and Natural Resources, State of Hawaii

32. Linn County, Iowa

33. Loudoun county government

34. Maryland-National Capital Park and Planning Commission

35. Manada Conservancy

36. Mid-America Regional Council - Regional Planning for Greater Kansas City

37. MD State Highway Administration 
38. Midpeninsula Regional Open Space District

39. Minnesota Department of Natural Resources

40. National Parks Conservation Association

41. New York State Department of Environmental Conservation

42. Open Space Institute, Inc.

43. Parish of Caddo

44. Patuxent Tidewater Land Trust

45. Prince Georges Soil Conservation District

46. Queen Anne's County Planning \& Zoning

47. Siskiyou Land Trust

48. St. Mary's County Government

49. Talbot County Maryland Planning and Permits Department

50. The Conservation Fund

51. The Hampshire County Farmland Protection Board

52. The Nature Conservancy

53. US Fish and Wildlife Service

54. US EPA Region 3

55. US Geological Survey

56. Whatcom Conservation District

57. Worcester County 


\section{Appendix B -Long Survey}

We are conducting a research study on conservation programs and attitudes towards applying optimization. The purpose of the survey is to figure out how conservation professionals have responded to the use of optimization in a variety of environmental contexts. The survey should take five to ten minutes to fill out. Participation is completely voluntary and all information will be kept confidential.

\section{Attitudes towards Adoption of Optimization in Conservation Planning}

1. Your name:

2. Name of your organization:

3. How knowledgeable are you regarding your organizations conservation program(s)? (Circle one)

\section{Not Knowledgeable Somewhat Knowledgeable Expert}
1
2
3
4 5

4. What software does you currently use (Circle ALL that apply)
a. GIS
b. Excel
c. SAS
d. Solver
e. Logic Scoring of Preferences - web version (LSPweb)
f. Optimization Decision Support Tool - Excel version (ODST Excel)
g. Optimization Decision Support Tool - web version (ODSTweb)
h. inVEST
i. Not applicable
j. Don't know

5. What software does your organization currently use for project selection? (Circle ALL that apply)
a. GIS
b. Excel
c. SAS
d. Solver
e. Logic Scoring of Preferences - web version (LSPweb)
f. Optimization Decision Support Tool - Excel version (ODST Excel)
g. Optimization Decision Support Tool - web version (ODSTweb)
h. inVEST
i. Not applicable
j. Don't know 


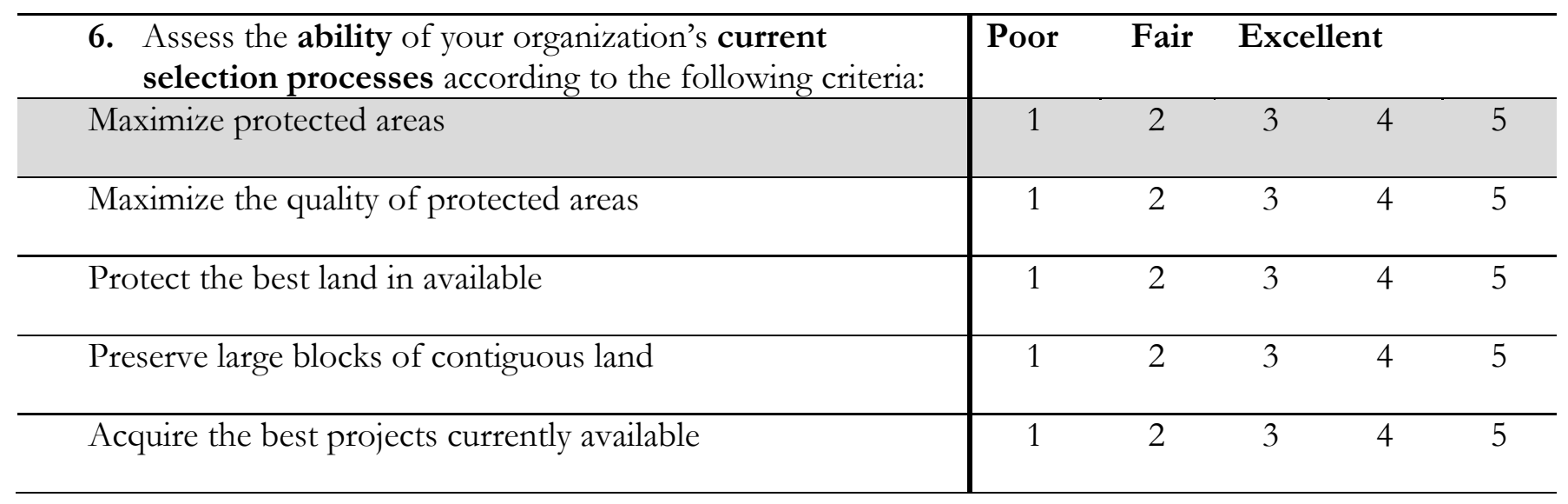

7. Please rate the following criteria in terms of importance:

Knowledge of staff on how to use your selection process

to identify good projects

Fairness to applicants

Transparency (ease of explanation to public, advisory

board, potential applicants, etc.)

Cost-effectiveness (achieve the largest possible social benefit for a relatively low price)

Ease of administration

Other:

\section{Low Medium High}

$\begin{array}{lllll}1 & 2 & 3 & 4 & 5\end{array}$

$\begin{array}{lllll}1 & 2 & 3 & 4 & 5\end{array}$

$\begin{array}{lllll}1 & 2 & 3 & 4 & 5\end{array}$

$\begin{array}{lllll}1 & 2 & 3 & 4 & 5\end{array}$

$\begin{array}{lllll}1 & 2 & 3 & 4 & 5 \\ 1 & 2 & 3 & 4 & 5\end{array}$

Poor Fair Excellent according to the following criteria:

Knowledge of staff on how to use your selection process to identify good projects

Fairness to applicants

Transparency (ease of explanation to public, advisory board, or potential applicants)

Cost-effectiveness (achieve the largest possible social benefit

\begin{tabular}{|ccccc}
\hline Poor & Fair & \multicolumn{2}{l}{ Excellent } & \\
\hline 1 & 2 & 3 & 4 & 5 \\
1 & 2 & 3 & 4 & 5 \\
\hline 1 & 2 & 3 & 4 & 5 \\
\hline 1 & 2 & 3 & 4 & 5 \\
\hline
\end{tabular}




\begin{tabular}{|c|c|c|c|c|c|}
\hline for a relatively low price & & & & & \\
\hline Ease of administration & 1 & 2 & 3 & 4 & 5 \\
\hline Other & & & & & \\
\hline
\end{tabular}

544 Optimization is a branch of economics and operations research studies that has shown

545 conservation professionals how to get more projectsconserved within a constrained budget or

546 achieve the same projects with a smaller budget. Optimization involves a set of mathematical

547 programming algorithms from operations research, such as binary linear programming and goal

548 programming. It is a process of including both monetized benefit information and acquisition costs

549 to identify projects that provide a high level of aggregate benefits at the best possible price ('getting

550 the most bang for the buck'). The optimization model evaluates each of the possible sets of available

551 projects and selects the set that maximizes the aggregate conservation benefits given a specified

552 budget maximizing the effectiveness of limited financial resources

553

554

555

556

557

558

559

560

561

562

563

564

565

566

9. Have you heard XXXX speak about optimization previously?
a. Yes
b. No

10. If yes, to question 9 , how much do you remember?

\begin{tabular}{ccccc} 
Nothing & \multicolumn{3}{c}{ Some } & Most \\
1 & 2 & 3 & 4 & 5
\end{tabular}

11. Have you heard read something XXXX about optimization previously?

a. Yes

b. No

12. If yes, to question 11, how much do you remember? Nothing
Some
Most
2
3
4
5

13. How well do you think you understand optimization overall? Not at all Somewhat Very well
1
2
3
4
5

14. How well do other people in your organization understand optimization?
Not at all
Somewhat
Very well
12
3
4
5

15. In general, do you think optimization is a good idea?

a. Yes

b. No, If no why not? 
16. Do you think optimization is applicable to your program?
a. Yes
b. No
c. Not sure

17. How willing do you think your organization would be to adopt optimizationas the selection processfor your conservation program in the future? Not at all
Somewhat
1
2
3
Very willing
4
5

18. Assess the difficulty of the following potential obstacles Not Difficult Somewhat Very Difficult for adopting optimization as the selection process in your organization's conservation program:

\begin{tabular}{|c|c|c|c|c|c|}
\hline Lack of previous experience & 1 & 2 & 3 & 4 & 5 \\
\hline Administration of the process & 1 & 2 & 3 & 4 & 5 \\
\hline Time to implement the process & 1 & 2 & 3 & 4 & 5 \\
\hline Need for accurate cost information at the time of selection & 1 & 2 & 3 & 4 & 5 \\
\hline Lack of availability of technical resources & 1 & 2 & 3 & 4 & 5 \\
\hline $\begin{array}{l}\text { Initial cost of technical resources costs (software and staff } \\
\text { training) }\end{array}$ & 1 & 2 & 3 & 4 & 5 \\
\hline Lack of incentives to justify a change in processes & 1 & 2 & 3 & 4 & 5 \\
\hline Possibly forgoing the 'best' project regardless of cost & 1 & 2 & 3 & 4 & 5 \\
\hline Due to Federal guidelines/ restrictions & 1 & 2 & 3 & 4 & 5 \\
\hline Difficulty in measuring benefits & 1 & 2 & 3 & 4 & 5 \\
\hline Other & & & & & \\
\hline
\end{tabular}

19. If your organization was given access to user-friendly Excel-based software to help implement optimization, how willing do you think your organization would be to adopt optimizationin the future?

20. If your organization was given access to user-friendly web-based software to help implement optimization, how willing do you think your organization would be to adopt optimizationin the future? 
596

597

598

599

600

601

602

603

604

605

606

607

608

609

610

611

612

613

614

615

616

$$
\text { Not at all }
$$

1
Somewhat

3
Very willing

45

21. If your organization was given access to $A N D$ trainingfor user-friendly software to help implement optimization, how willing do you think your organization would be to adopt optimizationin the future? Not at all

Somewhat

Very willing

1

2

3

4

5

\section{LSP Section}

22. Do you numerically score benefits of the conservation projects?
a. Yes
b. No

23. If you answered yes to 50 , how well do the numeric scored benefits reflect on the ground reality?
Not at all
Somewhat
1
2
3
Very well
45

Logic Scoring of Preference (LSP) is a scientifically rigorous technique to design project selection criteria and weightings and ensure that the benefits calculated accurately reflex the desired intent of decision makers.

24. Have you heard XXXX speak about LSP previously?
a. Yes
b. No

25. If yes, to question 55 , how much do you remember?
Nothing
Some
Most
12
3
4
5

26. Have you heard read something by XXXX about LSP previously?
a. Yes
b. No

27. If yes, to question 50 , how much do you remember? Nothing
Some
Most
12
3
4
5

28. How well do you think you understand LSP overall?

Not at all

Somewhat

Very well 
29. In general, do you think LSP is a good idea?

a. Yes

b. No, If no why not?

30. Do you think LSP is applicable to your program?

a. Yes

b. No

646

c. Not sure

31. How willing do you think your organization would be to adopt LSP as the selection processfor your conservation program in the future? Not at all

Somewhat

1

2

3

Very willing

45

\section{About your organization}

32. How many years have you worked for this organization?

33. Your current job title:

34. How many years have you been employed in this position?

35. What type of organization/agency do you work for? (circle one)
a. Federal agency
b. State agency
c. Local agency
d. National non-profit organization
e. Regional non-profit organization
f. Local non-profit organization
g. Consulting business
h. Other business
i. Other

36. What projects are of primary concerns for your organization/agency? Check all that apply. $\square$ Farmland conservation

$\square$ Historic conservation

$\square$ Forest conservation

$\square$ Open space conservation

$\square$ Park development

$\square$ Water protection

$677 \square$ Wildlife preservation 
678

679

680

681

682

683

684

685

686

687

688

689

690

691

692

693

694

695

696

697

698

699

700

701

702

703

704

705

706

707

708

709

710

711

712

713

714

715

716 $\square$ Military readiness

$\square$ Other

38. Where are the primary activities of your agency/organization in the United States? (circle all that apply)
a. Northeast
b. South
c. Midwest
d. Mid-Atlantic
e. West
f. International
g. Other
h. Not applicable

39. How many employees (full-time equivalents) has your organization employed in each of the following years:

$$
\begin{aligned}
& 2011 \\
& 2012 \\
& 2013:
\end{aligned}
$$

40. What have been the annual project budgets for your organization in each of the following years:

$\begin{array}{ll}2011 & \$ \\ 2012 & \$ \\ 2013: & \$\end{array}$

41. Are there any other thoughts you would like to share with us concerning your organization's current selection process, or the optimization selection process?

42. Would you like to be contacted to learn more about optimization?
a. Yes
b. No

43. Would you like to be contacted to learn more about LSP?
a. Yes
b. No 


\section{Appendix C -Short Survey}

We are conducting a research study on conservation programs and attitudes towards applying optimization. The purpose of the survey is to figure out how conservation professionals have responded to the use of optimization in a variety of environmental contexts. The survey should take five to ten minutes to fill out. Participation is completely voluntary and all information will be kept confidential.

Attitudes Towards Adoption of Optimization in Conservation Planning

1. Your name:

2. Please rate the following criteria in terms of importance:

Knowledge of staff on how to use your selection process

to identify good projects

\section{Low Medium High}

$\begin{array}{lllll}1 & 2 & 3 & 4 & 5\end{array}$

Fairness to applicants

1

$\begin{array}{llll}2 & 3 & 4 & 5\end{array}$

Transparency (ease of explanation to public, advisory

board, potential applicants, etc.)

$\begin{array}{lllll}1 & 2 & 3 & 4 & 5\end{array}$

Cost-effectiveness (achieve the largest possible social benefit for a relatively low price)

Ease of administration

$\begin{array}{llrr}2 & 3 & 4 & -5\end{array}$

$\begin{array}{lllll}1 & 2 & 3 & 4 & 5\end{array}$

Optimization is a branch of economics and operations research studies that has shown conservation professionals how to get more projectsconserved within a constrained budget or achieve the same projects with a smaller budget. Optimization involves a set of mathematical programming algorithms from operations research, such as binary linear programming and goal programming. It is a process of including both monetized benefit information and acquisition costs to identify projects that provide a high level of aggregate benefits at the best possible price ('getting the most bang for the buck'). The optimization model evaluates each of the possible sets of available projects and selects the set that maximizes the aggregate conservation benefits given a specified budget maximizing the effectiveness of limited financial resources

3. How well do you think you understand optimization overall?
Not at all
Somewhat
Very well
12
3
4

4. In general, do you think optimization is a good idea?

a. Yes

b. No, If no why not? 
5. How willing do you think your organization would be to adopt optimizationas the selection processfor your conservation program in the future?
Not at all
Somewhat
Very willing
1
2
3
4
5
6. Assess the difficulty of the following potential obstacles for adopting optimization as the selection process in your organization's conservation program:

Not Difficult Somewhat Very Difficult

\begin{tabular}{|c|c|c|c|c|c|}
\hline Lack of previous experience & 1 & 2 & 3 & 4 & 5 \\
\hline Need for accurate cost information at the time of selection & 1 & 2 & 3 & 4 & 5 \\
\hline $\begin{array}{l}\text { Initial cost of technical resources costs (software and staff } \\
\text { training) }\end{array}$ & 1 & 2 & 3 & 4 & 5 \\
\hline Lack of incentives to justify a change in processes & 1 & 2 & 3 & 4 & 5 \\
\hline Possibly forgoing the 'best' project regardless of cost & 1 & 2 & 3 & 4 & 5 \\
\hline Difficulty in measuring benefits & 1 & 2 & 3 & 4 & 5 \\
\hline
\end{tabular}

752

753

754

755

756

757

758

759

760

761

762

763

764

765

766

767

768

769

770

771

772

7. If your organization was given access to user-friendly software to help implement optimization, how willing do you think your organization would be to adopt optimizationin the future?
Not at all
Somewhat
12
3
4
Very willing
5

8. If your organization was given access AND TRAINING to user-friendly software to help implement optimization, how willing do you think your organization would be to adopt optimizationin the future?
Not at all
Somewhat
12
3
4
Very willing
5

9. Would you like to be contacted to learn more about optimization?
a. Yes
b. No

10. Do you have any comments or suggestions about this survey? 